\title{
MOLÉSTIAS DISMIELINIZANTES DO SISTEMA NERVOSO
}

\author{
Antonio B. Lefìvre * \\ Maria Irmina Valente ** \\ HEIENA WRONSKI **
}

As moléstias dismielinizantes constituem assunto que, nos últimos anos, vem merecendo grande atenção, particularmente nos setores de pesquisa relacionados com a patologia experimental. E' fácil compreender o motivo dêste interêsse, porquanto neste grupo incluem-se, além da esclerose múltipla que continua desafiando a argúcia dos terapeutas, as afecções relacionadas com as vacinações que, na Holanda e Inglaterra - para citar apenas os países em que sua incidência foi mais severa - chegaram a criar sério problema de saúde pública. Devemos reconhecer que alguma luz se vem projetando sôbre o assunto, embora ainda quase que exclusivamente em terreno de ordem experimental, podendo-se mesmo afirmar que já avançamos alguns passos além da etapa caracterizada por Russel Brain na frase pessimista de que "no presente estado de nossa ignorância pouco ou nada conhecemos sôbre os agentes causais destas afecçôes".

Ao pesquisador italiano Ferraro devemos boa parte do progresso já feito. Em trabalho publicado em 1944, completando idéias já anteriormente esboçadas, Ferraro chama a atenção para a extrema complexidade reinante neste capítulo, por fôrça da ação dos "caçadores de moléstias" para usar uma feliz fórmula de Wartenberg - os quais, com base em particularidades clínicas ou anátomo-patológicas pouco significantes, criaram uma infinidade de moléstias, que se distinguiam entre si, seja pelo caráter mais ou menos agudo, pela idade dos pacientes, por uma possível incidência familiar ou por fatôres mais ou menos obscuros, relacionados, na realidade, com a resistência individual dos tecidos nervosos.

Não desejamos entrar em minúcias sôbre os pormenores das pesquisas realizadas em terreno experimental por Ferraro, Cazzullo, Morgan, Roizin, Good, Jervis, Kabat, Koprowski, os Kopelhoff e tantos outros. Lembremos apenas que, mediante técnicas já bastante simplificadas, é possivel reproduzir em laboratório, por meio de injeções de emulsões cerebrais com

Trabalho do Serviço de Neurologia da Fac. Med. da Univ. de São Paulo (Prof. A. 'lolosa), apresentado no Departamento de Neuro-Psiquiatria da Associação Paulista de Medicina, em 8 agôsto 1951.

* Livre-docente de Clínica Neurológica na Fac. Med. da Univ. de São Paulo.

* Assistentes voluntárias do Serviço de Neurologia da Fac. Med. da Univ. de São Paulo. 
adjuvantes, os quadros clínicos e anátomo-patológicos dos vários tipos de moléstias dismielinizantes. Assim, vários quadros clínicos puderam ser observados, citando-se como mais importantes os seguintes: convulsões localizadas ou globais, fenômenos paréticos ou paralíticos, ataxias, dismetrias, vários graus de alteração da visão e mesmo cegueira completa. Foram reproduzidas formas clínicas variadas, tipo predominantemente cerebelovestibular, encefalomielítico difuso, oftalmoplégico, letárgico ou óptico. Em certos animais foram verificadas manifestações cerebelo-vestibulares e piramidais análogas às da esclerose múltipla; outro grupo mostrou um predomínio quase absoluto para as perturbações ópticas, com déficit mais ou menos acentuado da visão.

A analogia entre os quadros clínico-experimentais e os da patologia humana ainda mais se acentua pelo fato de que os animais mostram uma flutuação da sintomatologia clínica, com remissões e exacerbaçōes alternativas dos sintomas; esta analogia já havia sido salientada por Ferraro em 1944, quando teve oportunidade de estudar o cérebro de um menino acometido por encefalomielopatia pós-escarlatina, no qual foi observado um amolecimento difuso com reação inflamatória semelhante àquela da encefalomielite experimental.

Em linhas gera:s, nas encefalomielopatias experimentais, o processo se desenvolveria da seguinte forma: no ponto da injeção o antígeno é libertado lentamente da emulsão de cérebro, enquanto que a substância gordurosa é fagocitada pelos macrófagos. A lentidão do processo é bem evidenciada pelo achado de restos da emulsão, ainda seis semanas depois da injeção. $O$ antígeno libertado estimularia a formação de anticorpos anticérebro (antibrain antibodies), os quais, quando libertados na circulaçāo, entrariam em contacto e reagiriam com o tecido cerebral normal, determinando as lesões descritas na sede da reação. Os anticorpos atingem o tecido nervoso, aparentemente. pelos vasos sangüíneos, o que é demonstrado pela localização perivascular das lesões e, também, presumivelmente pelo líquiido cefalorraqueano, causando lesões subpiais e subependimárias. A formação de anticorpos é órgano-específica, mas não é espécio-específica, uma vez que foram obtidos resultados idênticos tanto com a suspensão de cérebro de macaco como com a de coelhos (ambas injetadas em macacos); em cobaias foi obtida reação utilizando emulsões com cérebros de coelhos.

A hipótese de um mecanismo alérgico na patogenia destas lesões vem tendo um número cada vez maior de adeptos entre os experimentadores, uma vez que há evidente analogia entre as manifestações clínicas e anátomo-patológicas das moléstias dismielinizantes e as decorrentes da anafilaxia experimental do sistema nervoso. E' certo, contudo, que existem ainda inúmeros problemas a resolver, entre os quais o de identificar qual seria o agente causal, na patologia humana das reações alérgicas das moléstias dismielinizantes. Ferraro, Cazzullo e Roisin realizam atualmente pesquisas baseadas no fato de que os elementos resultantes do metabolismo ali- 
mentar são muito semelhantes aos resultados do fracionamento da substância cerebral, aventando a hipótese da responsabilidade destas frações constituintes do bolo alimentar desintegrado como agentes desencadeantes da reação alérgica; as experiências que êstes pesquisadores estão realizando consistem em utilizar como antígeno estas frações de alimentos desintegrados, emulsionados juntamente ou sem mucosa intestinal.

Resta ainda por esclarecer o papel dos chamados coadjuvantes, que, na técnica original de Freund, eram os bacilos de Koch mortos pelo calor e emusionados com parafina; esta técnica foi modificada por outros autores, que têm utilizado outros agentes patogênicos, e uma emulsão oleosa especial ("Falba"). Embora não se conheça qual seja o papel desempenhado por estas substâncias coadjuvantes, uma coisa parece certa: a importância da presença da mielina na emulsão de cérebro usada como antígeno. Experiência recente de Wolff e Bezer demonstrou que a utilização de emulsões de cérebros jovens, ainda não mielinizados, mesmo com os adjuvantes, é incapaz de provocar encefalomielopatia.

$O$ rumo atual das pesquisas, depois de vencida a etapa da determinação experimental das encefalomielopatias, é o da prevenção destas moléstias experimentais por meio da dessensibilização, administrando extratos cerebrais, seja em doses únicas e grandes, seja em doses pequenas e progressivas. Os trabalhos de Ferraro e Cazzullo, dentre outros, já mostraram a segura possibilidade de se proteger os animais de experiência (cohaias e macacos) ; conseguiram êles, nos animais dessensibilizados, demonstrar a realidade desta proteção experimental, eja parcial - provocando formas atenuadas ou fugazes de encefalomielopatia - seja a total, isto é, impedindo completamente o aparecimento das manifestações clínicas e anátomo-patológicas.

Resta ainda bastante por fazer, mesmo no terreno experimental, mas devemos reconhecer que importantes passos já foram dados no sentido do agrupamento de um grande número de moléstias dentro do rótulo geral das moléstias dismielinizantes, bem como no de atribuí-las tôdas a uma patogenia alérgica comum.

As objeções principais dos que se opõem a esta hipótese patogênica se baseiam, principalmente, na incapacidade dos objetores de distirguir as alterações crônicas das agudas, esquecidos de que o estudo anátomopatológico de áreas de dismielinização mais recente que se desenvolvem nos casos de esclerose crônica, revelam os mesmos achados observados nos processos agudos de dismielinização. Ao lado dêste fato, devemos considerar que não há justificativa em considerar um processo como degenerativo apenas porque a infiltração perivascular é pequena, pois as experiências vieram mostrar que ela pode ser mais ou menos intensa, dependendo não sòmente da resistência individual como da idade do processo. A hipótese explicativa de Putnam e Alexander, em lugar de se opor, é mais um argumento em favor da patogenia alérgica, pois foi verificada a formação 
de trombos na anafilaxia experimental da pele, das articulações, do pulmão, do coração e do cérebro, podendo-se observar todos os estágios na formação de tais trombos.

Diante desta massa de trabalhos realizados pclos cxperimentadures e patologistas poderíamos perguntar o que fizemos nós os clínicos ante esta grande via que parece se abrir para a terapêutica de um sem número de moléstias? Muito pouco, é forçoso reconhecer. Só agora é que a clínica procura oferecer alguma contribuição prática. Recentemente (1949), Pichar e Kramer trataram um caso de encefalite produzido pela vacinação anti-rábica, pelo Benadryl e outro anti-histamínico to cloridrato de triplenamina), obtendo excelente resultado; êstes autores sugeriram aos clínicos o emprêgo dêste tipo de terapêutica para casos semelhantes.

Os neurologistas, bem como os clínicos gerais e, mais particularmente. os pediatras, têm visto casos de difícil explicação pelos critérios clínicos tradicionais. Certos pacientes que sùbitamente apresentam quadros gravíssimos, com estado de coma precocemente instalado, com ou sem convulsões, com manifestações de ordem neurológica mais ou menos difusas, ou então com sinais focais extremamente variáveis de um dia para outro, e com evolução rápida para a morte ou então para uma cura surpreendente e aparentemente miraculosa; êstes quadros clínicos que lembram muito as manifestações da encefalopatia pós-vacinal (particularmente os relacionados com a vacinação antivariólica) são bastante comuns. Já temos visto alguns dêles e devemos reconhecer que freqüentemente ficamos inteiramente desarmados tanto no que diz respeito ao diagnóstico quanto à terapêtutica e ao prognóstico; os exames complementares; inclusive o de líqüido cefalorraqueano, são em geral pouco ou nada esclarecedores, e ao clínico nada resta senão um diagnóstico vago e insatisfatório de encefalite, não obstante trabalhos recentes terem mostrado que êste rótulo é freqüentemente empregado de maneira inteiramente infundada (Adams e Weinstein).

Não é nosso intuito avançar qualquer conclusão sôbre a terapêutica por meio dos anti-histamínicos ou dos vários processos de dessensibilização. O que não parece justificável é a passividade com que os clínicos muitas vêzes enfrentam casos dêste tipo. Não é compreensível a razão do esquecimento desta terapêutica que a experimentação está francamente indicando. Recentemente (1949), Dusscher e Radermecker, do Irstituto Bunge, publicaram a observação de um caso em que se desenvolveu uma mielopatia ascendente. com fenômenos também encefálicos, em seguida a uma dupla vacinação (jenneriana e antitífica); o quadro clínico se desencadeou de forma agudíssima, reproduzindo nitidamente os quadros clínico-experimentais a que nos referimos, levando o paciente ràpidamente à morte. 0 exame anátomo-patológico mostrou tratar-se de uma encefalomielopatia difusa de tipo dismielinizante, com lesões principalmente medulares, análogo aos quadros provocados experimentalmente. A terapêutica empregada, entretanto, foi, "faute de mieux" (para usar a própria expressão dos au- 
tores), o sôro de Petit; não deixa de ser curioso recordar que, nos 5 dias de evolução que a moléstia teve, houve oportunidade de verificar nítida regressão, embora passageira, dos sintomas sensitivos, motores e psíquicos; êste registro torna-se ainda mais curioso se recordarmos que os autores, nos comentários finais de sua publicação, aproximam êste seu caso daqueles conseqüentes às vacinações e às moléstias relacionadas com as afecções chamadas próprias da infância (sarampo, etc.).

No mesmo Instituto Bunge, ainda em 1949, Liessens fêz uma revisão sôbre os acidentes nervosos periféricos conseqüentes à soroterapia $\mathrm{e}$ às vacinações, por ocasião da publicação de um seu caso de paralisia braquial periférica em um menino de 8 anos submetido à revacinação pelo toxóide diftérico; êste caso foi bem estudado, tendo a paralisia sido confirmada em seu caráter periférico pela cronaximetria. $O$ autor, entretanto, apesar de se confessar adepto da patogenia alérgica para esta complicação rara de vacinação, chegando mesmo a se referir a um trabalho de Bourguignon em que foi verificada uma predisposição familiar para êste tipo de manifestações (tal como para outras manifestações alérgicas), não realizou qualquer tentativa terapêutica orientada em um sentido específico, se assim podemos dizer, levando-se em conta a patogenia admitida.

Parece muito oportuno repetir a sugestão de Pichar e Kramer acima citada, pois a terapêutica mais lógica que se pode propor para estas moléstias, desde que admitamos a patogenia alérgica, só pode ser aquela que vise e mecanismo patogênico, procurando atuar contra a reação alérgica. $O$ emprêgo de anti-histamínicos poderá ou não ser aprovado pela prática clínica, mas o que parece fora de dúvida é que êstes medicamentos deverão ser empregados em um grande número de casos, particularmente tendo em conta sua inocuidade.

Este grupo de medicamentos deverá dominar a terapêutica dêstes quadros dismielinizantes, pelo menos até que se demonstre a sua ineficiência, levando-se em conta principalmente que não há qualquer outra medicação que possa ser lògicamente empregada.

Entretanto, torna-se necessária longa experiência clínica antes de qualquer conclusão definitiva, pois é conhecido o fato de que estas moléslias. com certa freqüência, regridem espontâneamente de maneira total ou parcial.

A apresentação de alguns casos destas moléstias nos permitirá salientar aspectos do quadro clínico e da terapêutica.

1) Mielopatia como complicação da varíola - As perturbações neurológicas conseqüentes à varíola podem ser consideradas raras, particularmente se levarmos em conta que esta moléstia se vem tornando dia a dia menos freqüente; segundo Russel Brain, a incidência é de cêrca de 2,5 para cada mil casos. Os quadros clínicos apresentados podem ser divididos em dois grupos principais: a) Encefálicos, caracterizados principalmente 
por distúrbios da linguagem que se manifestam quando o paciente sai do torpor determinado pela encefalopatia, sendo de notar que esta afasia regride lentamente; o prognóstico quanto à vida é henigno nestes casos; b) Mielopáticos, caracterizados por paralisias, acompanhadas ou não de distúrbios esfinctéricos; neste grupo a mortalidade é elevada, pois dentre os 7 casos referidos por Mardsen e Hurst, 3 tiveram êxito letal.

Caso 1 - A. C. C., com 10 anos e 6 mieses de idade, branco, sexo masculino. Antecedentes pessuais e faniliares sem interêsse. Desenvolvimento normal até o início da moléstia atual. Ém 16-8-1950 o paciente apresentou lesões cutâneas características da varíola, sendo o tratamento iniciado no próprio domicílio; seis dias depois amanheceu com diminuição da fôrça muscular nos dois membros in. feriores, não conseguindo manter-se de pé ou mesmo sentado no leito, sem apôio. Nessa noite teve uma crise de contrações espasmódicas no membro inferior esquerdo, com duração de algumas horas, seguida de parilisia completa dos dois unembros inferiores, retenção dẹ urina e de fezes. Foi então internado no Hospital Emílio Ribas, onde permaneceu até 18-9-1950, época em que foi transterido para a Clínica Neurológica do Hospital das Clínicas da Fac. Med. da Univ. de São Paulo. O exame feito por ocasião da internação mostrou: paciente calmo, consciente, com desenvolvimento nental próprio da idade; paraplegia crural, flácida, atingindo a paralisia a musculatura glútea e abdominal. Todos os reflexos profundos encontravam-se abolidos, estando também ausentes os cremastéricos (superficiais e protundos) e os cutâneo-abdominais; sinal de Babinski bilateral. Nog membros st:eriores foi observada paresia atingindo ambas as mãos, com déficit dos movimentos de flexão, adução e abdução dos dedos; havía discreta atrofia dos interósseos e achatamento das eminências tênar e hipotênar; os reflexos estiloradial e bicipital não foram obtidos. Os exames subsidiários mostraram: reações do líqüido cefalorraqueano dentro dos limites da normalidade; hemograma com desvio à esquerda.

Fui instituída terapêutica pelo Benadryl, complexo B, massagens, movimentação passiva, profilaxia de escaras. Durante a evolução foi observado edema trófico nos membros inferiores e escari glútea. A pós dois nıeses de evolução a paraplegia apresentava-se espástica, havendo mesmo tendência à contratura em flexão da coxa sôbre a bacia; o paciente conseguia dar alguns passos, apoindo; os esfíncteres retal e vesical apresentavam-se incontinentes. Nos membros superiores havia apenas ligeira diminuição da fôrça muscular na mão direita. O paciente foi então encaninhado à Clínica Ortopédica, onde foi colocado aparêlho para a correção da atitude anormal da coxa, sendo submetido a tratamento especial para reabilitação. Foi visto novamente em maio de 1951 , observando-se então que a paralisia havia regredido quase totalmente, sendo normal o contrôle dos csfíncteres; o paciente andava com facilidade e sem apôio.

2) Encefalopatia como complicação do sarampo - E' bem mais freqüente do que a conseqüente à varíla. Hoyne, de Chicago, refere a proporção de 1:428 casos de sarampo ocorridos naquela cidade; Jacobson verificou a incidência de 1:8,2 em janeiro-fevereiro de 1949, e um total de 1:95 entre todos os casos de sarampo registrados no hospital para moléstias infecciosas de Estocolmo no intervalo compreendido entre 1925 e 1949. Analisando vários trabalhos publicados sôbre o assunto verificamos os seguintes dados principais: a) a afeç̧ão incide indiferentemente em qualquer idade, sendo óbvio que, como o sarampo é mais comum na infância, as complicações do mesmo são também mais freqüentes entre as crianças; 
b) não há diversidade de incidência relacionada ao sexo; c) parece que esta complicação respeita a raça negra, pois, entre 314 pacientes de sarampo observados por Hoyne, 88 eram negros e nenhum apresentou encefalopatia; d) relacionando a época de aparecimento dos sinais de comprometimento do sistema nervoso central com o início do exantema, verifica-se que tais distúrbios são mais freqüentes entre o $3 .^{\circ}$ e o $7 .^{\circ}$ dias, menos freqüentes entre os $15 .^{\circ}$ e $17 .^{\circ}$ e mais raros ainda no $10^{\circ}$ dia, sendo raríssimos os casos em que os sinais neurológicos precedem o exantema.

O quadro clínico das complicações nervosas do sarampo é dos mais variáveis, podendo iniciar-se abrupta ou insidiosamente. Os sinais decorrem da porção do sistema nervoso que foi atingida, podendo haver sinais meníngeos, encefálicos ou medulares, bem como formas mistas. $O$ quadro mental varia entre a simples prostração e o coma, ou grande irritabilidade. As convulsões ocorrem com bastante freqüência, enquanto que as paralisias parecem ser bastante raras. $O$ líqüido cefalorraqueano apresenta-se alterado de forma variável; há hipercitose de grau variável com linfomonucleose, podendo ocorrer também aumento mais ou menos acentuado da taxa de proteínas.

A melhor orientação para o diagnóstico de um quadro que pode assumir aspectos tão variáveis consiste, como é óbvio, no estabelecimento de uma relação causal com o sarampo, desde que existam manifestações precedentes e próximas desta afeç̧ão. Parece estabelecido que a maior ou menor gravidade do quadro clínico do sarampo não condiciona, proporcionalmente, maior ou menor gravidade da afecção neurológica subseqüente. De modo geral a mortalidade não é muito elevada: a média de $10 \%$ pode ser considerada como a mais próxima da realidade. A percentagem de seqüelas é também de cêrca de $10 \%$.

Por não haver ainda coincidência de pontos de vista quanto à etiopatogenia, a terapêutica varia de um para outro autor. Medidas terapêuticas com finalidade de reduzir o edema cerebral, a administração de sôro de convalescentes, de $\gamma$-globulinas, etc., têm sido empregadas com resultados variáveis. Recentemente, Florêncio Bazan empregou os anti-histamínicos em 5 casos, com "resultados extraordinários", embora fazendo ressalva em face do pequeno número de casos.

Caso 2 - A. P. D., com 5 anos de idade, branco, sexo masculino. Antecedentes pessoais e familiares sem interêsse. Desenvolvimento psicomotor normal até o início da moléstia atual. Em 20 de abril de 1951 apresentou-se com quadro clínico característico de sarampo, seguido, cêrca de 24 horas após o início da manifestação dos exantemas, de convulsões de tipo clônico, de longa duração, acompanhadas de cianose e relaxamento dos esfíncteres; estas convulsões repetiram-se várias vêzes com pequenos intervalos. Foi então o paciente internado no Hospital Emílio Ribas, onde permaneceu durante 16 dias. Ao ser internado na Clínica Neurológica do Hospital das Clínicas da Fac. Med. da Univ. de São Paulo apresentava-se em péssimo estado geral, apático, indiferente ao meio, só atendendo quando repetidamente solicitado. Articulava apenas algumas palavras, com voz monótona, nıantendo-se quase que permanentemente em chôro. Não havia parali- 
sia alguma, porém a movimentação era escassa e executada com fôrça muscular muito débil, acompanhada de tremor; o exame da movimentação passiva mostrava discreta hipertonia no início dos movimentos, seguida de hipotonia. O paciente não se mantinha sentado nem de pé, mesmo com apôio. Os reflexos protundos eram vivos, principalmente à direita; sinal de Rossolimo bilateral; reflexos cutâneos com respostas vivas e simétricas. $O$ exame do líqüido cefalorraqueano não mostrou anormalidades; o hemograma apresentava desvio à esquerda e eosinofilia.

A terapêutica empregada constou de cuidados gerais (dieta hiperprotêica e hipervitamínica), antibióticos (penicilina) e placiglobulina, da qual recebeu 6 injeções intramusculares de $2 \mathrm{ml}$. $O$ paciente teve alta no $20.0^{\circ}$ dia de tratamento, completamente curado tanto sob o ponto de vista neurológico como psíquico. A linguagem restabeleceu-se completanıente. Torna-se interessante assinalar que o início da melhora clínica teve estreita correlação com a administração da placiglobulina.

Caso 3 - A. G., com 4 anos de idade, branco, sexo masculino. Nos antecedentes pessoais apurou-se o seguinte: criança nascida a têrmo, de parto eutócico, após gestação normal. Ausência de asfixia neonatal. Evolução normal até os 3 anos de idade, época em que, sem qualquer causa aparente, apresentou crise convulsiva de caráter clônico atingindo o hemicorpo direito; esta crise durou cêrca de 4 horas. Durante um ano teve, por cinco vêzes, crises convulsivas, sempre com os mesmos característicos. Em fins de dezembro de 1950 teve sarampo e, 15 dias após, apresentou crise convulsiva generalizada, de tipo clônico, sucedida de outras com caráter subintrante, ficando neste estado durante 8 horas. Ao recobrar a consciência apresentava hemiplegia direita e afasia. A partir dêste momento não mais apresentou crises convulsivas do tipo descrito mas sim crises curtas, que os pais descreviam como "choques", com duração de segundos, não seguidas de perda de consciência. Foi internado na Clínica Neurológica do Hospital das Clínicas da Fac. Med. da Univ. de São Paulo em 23-2-1951. Ao exame constatou-se criança em ótimo estado geral, apresentando hemiplegia direita, total, proporcional. O tono muscular era normal. Os reflexos profundos estavam presentes e simétricos, com exceção do patelar que tinha caráter pendular à direita. Sinal de Babinski à direita. Afasia de expressão sem aparente componente perceptivo; o paciente fazia-se entender por gestos, dando nítida demonstração de que entendia o que se lhe dizia. Os exames complementares revelaram o seguinte: líquiido cefalorraqueano normal; hemograma com leucocitose e desvio à esquerda; hemossedimentação elevada (43 mm na primeira hora); o EEG mostrou foco extenso frontocentral esquerdo; craniograma normal; a pneumoventriculografia mostrou hidrocefalia ex-vácuo, por atrofia e cicatriz meningo-cortical.

Como terapêtica foram empregados anticonvulsivos ('Tridione e Gardenal), reeducação da linguagem e reeducação muscular. Por ocasião da alta foi assinalada regressão acentuada da afasia e regressão parcial da hemiplegia, particularmente no membro inferior, que havia readquirido boa parte de sua movimentação voluntária. As convulsões estavam sendo controladas com a medicação.

3) Complicações nervosas nas vacinações - 0 quadro clínico das complicações nervosas pós-vacinais é grandemente variável, pois as manifestações podem ser tanto de ordem periférica como central, assumindo, neste último caso, características de uma síndrome piramidal, extrapiramidal ou mista.

Sua incidência é, também, muito variável, não sòmente de um país para outro, como também em um mesmo país em épocas diversas. Aa lado de estatísticas altamente alarmantes como a assinalada na Holanda, onde, 
em certa época, foi verificada a incidência de uma complicação neurológica para cada 4.000 vacinaçóes, ou mesmo uma estatística inglêsa que mostrou a incidência de 1:36.000 vacinações, há certos países, como a Rússia e os Estados Unidos da América do Norte, onde a vacinação é feita em grande escala e as complicações são muito raras. Levando em conta que vacinas da mesma procedência determinaram complicações nervosas quando utilizadas na Holanda e não na Espanha, podemos admitir a possibilidade de um fator, não conhecido, agindo como elemento adjuvante em alguns países. Não dispomos de qualquer informação sôbre a incidência destas complicações em nosso país.

Não há qualquer relação determinada com o sexo e a côr dos pacien. tes, mas parece haver nítida relação com a idade, estando demonstrado que a incidência é bem maior entre os 3 e 12 anos de idade. Tanto as vacinações como as revacinaçōes podem provocar a complicação, porém na primovacinação ela é mais freqüente na proporção de 1:20 em comparação com a revacinação. Digno de nota, pelo seu grande valor prático, é o fato de que as complicações são excepcionais em crianças no primeiro ano de vida. 0 tempo de incubação é variável entre 2 e 30 dias, sendo digno de menção o fato de que, nas revacinações, o tempo de incubação é bem mais curto do que nas primovacinações.

0 quadro clínico, freqüentemente, inicia-se de maneira abrupta, entrando o paciente em coma após uma evolução de poucas horas. A evolução da moléstia é, em geral, de uma a duas semanas, e o quadro clínico é caracterizado principalmente por estado de torpor mais ou menos pronunciado, intercalado com períodos de agitação psicomotora que pode ser bastante intensa. Os sinais focais são de tal maneira variáveis que se torna difícil pretender fazer uma descrição pormenorizada; podem ser observados distúrbios do tono muscular, hipercinesias transitórias e, mesmo, déficit motor de distribuição mais ou menos difusa. Em um mesmo paciente o quadro clínico varia muito, algumas vêzes no curso de 24 horas. As seqüelas podem ser mais ou menos graves; parece não haver relação entre o prognóstico e a gravidade do quadro clínico inicial; casos de início muito grave, mesmo que o estado de coma dure alguns dias, podem evoluir para cura completa, sem qualquer seqüela. A mais elevada mortalidade foi observada na Inglaterra, com 58\% de óbitos, e a menor na Suíça, com $20 \%$.

$O$ fato de não existir especificidade do quadro clínico relacionada com o tipo de vacina, reforça a convicção daqueles que incluem estas complicações dentro de um único grupo com o denominador comum de uma mesma patogenia.

Caso 4 - F. D., com 1 ano de idade, masculino, branco. Menino eutrófico, sem antecedentes pessoais dignos de menção, foi vacinado contra varíola estando em plena saúde. A vacinação evoluiu sem incidentes até o 10.9 dia, quando o paciente apresentou-se em torpor pouco profundo e com a hemiface direita para- 
lisada. $O$ exame neurológico mostrou, além do estado de torpor, nítida mudança do humor, pois o menino, que era alegre e brincalhão, tornou-se resmungador e negativista; foi verificada paralisia periférica do nervo facial à direita; ausência de parlisias nos membros, bem como de perturbações para o lado de outros nervos cranianos.

Foi instituída terapêutica pelo Benadryl (xarope) na dose de 4 colheres das de chá por dia, e vitamina $B_{1}(50 \mathrm{mg}$ ao dia). Ao fim de 10 dias foi iniciada a eletroterapı. Evolução gradual no senticlo da melhora; o estado mental apresentou melhoras logo no início do tratamento, retornando à completa normalidade; a paralisia facial regrediu totalmente ao fim de mês e meio. A terapêtica pelo Benadryl foi mantida durante 15 dias.

Caso 5 - V. L. G., com 13 meses de idade, branca, sexo feminino. Menina eutrófica, sem antecedentes pessoais dignos de menção; já andava sem apôio e falava 3 ou 4 palavras no início da moléstia. A vacinação antivariólica foi teita estando a paciente em plena saúde; ao fím de 8 dias começou a apresentar hipertermia e, 12 dias após a vacinação, os pais verificaram que a paciente não movia mais os membros direitós, não tendo sido observada qualquer perturbação da linguagem ou da palavra. Ao exame foi verificado que a criança se apresentava levemente entorpecida, normotérmica, com discretos sinais de meningismo e com grande redução da movimentação espontânea ou estimulada dos membros do hemicorpo direito. Ausência de paralisia na face ou de lesão de outros nervos cranianos. Reflexos profundos totalmente abolidos, tanto no hemicorpo direito como no esquerdo; ausência de resposta dos reflexos cutaneoplantares. $O$ exame de líquor revelou discreta hipercitose $\left(5,8 \mathrm{cels} / \mathrm{mm}^{3}\right)$ com $100 \%$ de linfócitos e precipitação na zona média da reação do benjoim coloidal.

A terapêutica instituída foi a seguinte: Aureomicina (Spersoids) na dose de 6 colheres das de chá ao dia, Benadryl (xarope) 6 colheres das de café ao dia e cloro-cálcio na dose de 40 gôtas ao dia; a administração da Aureomicina foi suspensa ao fim de 24 horas por intolerância. Uma semana depois o torpor havia cedido completamente; c déficit do membro inferior havia regredido bastante, já podendo o paciente manter-se de pé e trocar alguns passos. O membro superior continuava ainda francamente deficitário, notando-se tendência à espasticidade, embora os reflexos estivessem ainda abolidos. Novo exame ao fim de 26 dias de moléstia, durante os quais foi mantida a terapêutica pelo Benadryl, clorocálcio e complexo de vitamina $B$, revelou francas melhoras. $O$ déficit do membro inferior era pràticamente imperceptível: o paciente andava bem, sem apôio, com marcha normal; os reflexos profundos eram normais, vivos e simétricos nos dois membros inferiores. $O$ déficit do membro superior estava bastante reduzido, notando-se apenas dificuldade para elevar o membro acima do plano correspondente ao ombro; a fôrça muscular era normal e a coordenação dos movimentos, satisfatória; os reflexos profundos continuavam abolidos nos dois membros superiores. Estado mental plenamente satisfatório.

Caso 6 - T. O., com 2 anos de idade, amarela, sexo feminino. A paciente foi vacinada contra a varíola estando em perfeita saúde; quatro ou cinco dias depois apresentava-se febril, com erupção generalizada pclo corpo e estado de torpor; apresentaram-se, enı seguida, crises convulsivas localizadas no hemicorpo esquerdo, seguidas de hemiplegia de igual localização. Esta hemiplegia era, de início, de caráter flácido, com abolição de todos os reflexos profundos e presença do sinal de Babinski. De todos os exames de laboratório apenas o tempo de coagulação mostrou-se anormal; em repetidos exames feitos conı várias técnicas diferentes foi verificado um tempo de coagulação reduzido à metade ou, no máximo, a $2 / 3$ do normal. Foi instituída, em vista dêste resultado, a terapêtica pela Heparina por via intravenosa, procurando-se controlar o tempo de coagulação; esta terapêtica foi feita irregularmente em vista das grandes dificuldades 
cncontradas para a prática da injeção intravenosa. A evolução se deu no sentido de melhora parcial; ao fim de três meses a hemiplegia havia regredido em parte, ao mesmo tempo que assumia caráter espástico; o déficit havia regredido principalmente nos segmentos proximais dos menıbros, notando-se ainda franco déficit da motricidade voluntária na mão e no pé esquerdos; os reflexos patelar e tricipital eram obtidos, ao passo que o sinal de Babinski foi substituído pela resposta normal do reflexo cutaneoplantar. Durante a evolução a paciente apresentou algumas crises convulsivas de caráter global e de tipo não muito característico.

Caso 7 - A. A. L., com 6 anos de idade, branco, sexo masculino. Nos antecedentes pessoais havia referências à ocorrência de raras crises convulsivas, de tipo não bem característico, manifestadas desde os três meses de idade. Em abril de 1950 foi aplicada a primeira dose de vacina antitífica, tendo o paciente apresentado, em seguida, hipertermia, torpor e crises convulsivas. Tendo cedido espontâneamente esta sintomatologia, foi feita, 20 dias após, a segunda dose de vacina, seguida desta vez de sintomatologia grave, com um quadro hipercinético misto, tendendo para o tipo do espasmo de torção, cim disartria bastante intensa, que tornava quase ininteligível a palavra. Foi tratado com Aureomicina, ácido nicotinico e Benadryl (xarope) na dose de 2 colheres das de chá, 4 vêzes ao dia. A sintomatologia regrediu totalmente. Em novembro de 1950 a sintomatologia reapareceu, coincidindo com uma emoção muito forte sofrida pelo paciente, que esteve na iminência de se afogar em um rio onde brincava. Foi então internado na Clínica Neurológica do Hospital das Clínicas da Fac. Med. da Univ. de São Paulo, onde foi submetido a várias terapêuticas inclusive anti-histamínicos, sem resultado. A sintomatologia sòmente regrediu com a piretoterapia feita pelo Termogênio, tendo sido submetido a 9 crises de hipertermia. Este paciente foi visto, pela lütima vez, em fins de julho de 1951, tendo sido o exame neurológico inteiramente normal nesta ocasião.

\section{COMENTARIOS}

Analisando, em conjunto, as nossas observações, pode-se notar como são variáveis as manifestações neurológicas, mesmo aquelas relacionadas com um único agente etiológico, como seja, por exemplo, a vacinação antivariólica. Ao lado de um paciente (caso 4) que apresentou, pràticamente, apenas uma paralisia facial de tipo periférico, um outro (caso 6) apresentou um quadro de sofrimento encefálico grave que teve como conseqüência uma hemiplegia duradoura e convulsões que persistiram mesmo quando a perturbação motora estava em franca regressão. Um paciente (caso 1) apresentou um quadro exclusivamente mielopático em seguida à varíola, com manifestações paralíticas graves que só regrediram após intenso tratamento, enquanto que os dois que sofreram complicações nervosas relacionadas com o sarampo apresentaram quadros bastante diversos quanto à gravidade, mas ambos traduzindo sofrimento encefálico (casos 2 e 3). Parece interessante chamar a atenção para o fato de que o paciente A. G. (caso 3) já apresentava anteriormente convulsões localizadas no hemicorpo direito, o que fazia supor a existência de lesão no hemisfário esquerdo cuja causa não pôde ser apurada; acreditamos que êste foco lesional antigo estendeu-se e agravou-se como conseqüência da encefalopatia 
pós-sarampo, transformando o paciente de simples convulsivo em um convulsivo com hemiplegia e afasia de expressão.

Com relação à idade dos pacientes devemos assinalar que dois dos quatro pacientes que apresentaram complicações nervosas conseqüentes à vacinação antivariólica tinham 12 e 13 meses de idade; se bem que o número de nossos pacientes seja insuficiente para qualquer dedução com valor estatístico, não deixa de ser interessante o fato de que crianças tão jovens tenham apresentado complicações, contrariando aquilo que se poderia supor em face do que parece estabelecido pelos que têm experiência maior; dêstes quatro casos, dois (casos 6 e 7) apresentaram complicações graves e duradouras.

No que diz respeito à terapêutica empregada destacamos o fato de que os casos $1,4,5$ e 7 foram tratados com anti-histamínicos; uma forma grave de mielopatia pós-variólica (caso 1) evoluiu para cura após longo tratamento, enquanto que dois casos de complicação nervosa pós-vacinação antivariólica (casos 4 e 5) evoluíram também para a cura, porém com um período de evolução bem mais curto. Um paciente com um quadro hipercinético bastante grave respondeu mal a esta medicação, tornando-se necessário a utilização de outra terapêutica (piretoterapia pelo Termogênio), com a qual se conseguiu a remissão da sintomatologia; devemos assinalar que, após a apresentação dêste trabalho, êste último paciente retornou à Clínica Neurológica do Hospital das Clínicas, com recidiva do quadro hipercinético após cêrca de seis meses em que passou bem, sem apresentar qualquer sintoma. Um dos pacientes (caso 2) de encefalopatia pós-sarampo foi tratado com imunoglobulina, com o que se obteve cura clínica completa; utilizamos esta terapêutica aproveitando a experiência de um outro caso por nós tratado com imunoglobulina e que, igualmente, alcançou cura completa com o desaparecimento de grave sintomatologia pirâmido-extrapiramidal.

O resultado satisfatório obtido nos casos tratados com anti-histaminicos parece autorizar o prosseguimento de tentativas terapêuticas orientadas neste sentido, para que futuramente possamos, com número maior de casos, fazer juízo seguro sôbre o que hoje nos parece uma promissora hipótese de trabalho.

\section{RESUMO}

Depois de analisar em conjunto os vários aspectos clínicos das moléstias dismielinizantes do sistema nervoso os autores procuram expor as várias hipóteses etiopatogênicas, detendo-se principalmente na análise da. quela aventada por Ferraro e outros, que atribuem a estas moléstias uma patogenia alérgica. Vários argumentos de ordem clínica e experimental que sustentam esta hipótese são expostos e analisados. Os autores apresentam 7 observações pessoais, sendo quatro de complicações rervosas de- 
vidas à vacinação (três após vacinação antivariólica e uma após vacinação antitífica), duas relacionadas com sarampo e uma com varíola. Em quatro dêstes casos foi tentada a terapêutica por meio de anti-histamínicos, sendo que, em três, os resultados foram bastante satisfatórios. Com base nestes casos os autores propõem que sejam continuadas as observações neste sentido com o fito de que, com número maior de casos, se torne possível juízo mais seguro sôbre o valor desta terapêutica.

\section{SUMMARY}

After analysing as a whole the different clinical aspects of the demyelinating diseases of the nervous system, the authors try to explain the various etiopathogenetic hypothesis, chiefly analysing that of Ferraro and others, which attributes to those diseases an allergic pathogenesis. Various clinical and experimental arguments which sustain that hypothesis are exposed and analysed. The authors present 7 personal observations from which 4 are the result of vaccination ( 3 after smallpox and one after typhus vaccination), 2 related to smallpox and one to measles. In four of the cases the antihistaminic treatment was tried, the results being very satisfactory in three cases. Based on these cases the authors propose that the observations should be continued in order to better judge the value of this treatment, on the basis of a larger number of cases. 